\title{
Guidelines to Development Wellness Tourism in Roi-Kaen-San-Sin Cluster, Thailand
}

\author{
Thirachaya Maneenetr \\ Director of Center for Asia-Pacific Tourism Research, Faculty of Management Science, Khon Kaen University \\ Email: thirachaya@kku.ac.th \\ Aree Naipinit \\ Faculty of Management Science, Khon Kaen University \\ Email: thirachaya@kku.ac.th \\ Thanh Ha Tran \\ Master Degree of Tourism Management, Faculty of Management Science, Khon Kaen University \\ Email: cholly.pen@gmail.com
}

\section{Doi:10.5901/mjss.2014.v5n23p214}

\section{Abstract}

The aim of this study is to investigate tourists' opinions on wellness tourism in Roi-Kaen-San-Sin cluster, Thailand and guidelines to develop wellness tourism in Roi-Kaen-San-Sin cluster, Thailand. Mix method was applied to ensure the research objective. Quantitate data collection is from questionaire of 400 tourists and qualitative data is collected from focus group discussion. The results showed that on overall, tourists' opinions on wellness tourism in Roi-Kaen-San-Sin cluster is at a high level in which attraction, attitude and accommodation are at the highest level while activities and advertising are at the high level and accessibility, amenities and advertising are all at a moderate. The guidelines to develop wellness tourism in RoiKaen-San-Sin cluster is comprised 1) improving facilitates for tourists 2) promoting wellness tourism through advertising activities 3) publish map direction of wellness destination in Roi-Kaen-San-Sin cluster and 4) diversity wellness activities for tourists.

Keywords: Tourism destination, Wellness tourism

\section{Introduction}

Le Serre (2008) highlighted that in the twenty-first century, the tourism industry faces a changing and competitive environment resulting from environmental catastrophes, information technology developments, greater competition between airline companies, and aging demographics. A successful destination strategy should have the ability to increase tourism expenditure, increase visitor numbers, and provide satisfying, memorable experiences. This should be done in combination with enhancing the wellbeing of the destination's residents and preserving the natural capital (Hartwell, 2014). That is the reason why wellness tourism comprises a broad range of tourist motivations and benefits of the product, today (Pesonen, \&Komppula, 2010). Wellness tourism was defined as the sum of all the relationships resulting from a journey by people whose motive to maintain or promote their health and well-being, and who stay at least one night at a facility that is specifically designed to enable and enhance people's physical, psychological, spiritual and/or social well-being (Voigt et al., 2011). In several countries, wellness or wellbeing tourism establishments are often located in a rural environment which nature experiences are an essential part of the wellbeingexperience (Pesonen, \&Komppula, 2010).

In term of Thailand, health and wellness tourism in Thailand showed impressive current value growth due to the positive response from incoming tourists (Euromonitor International, 2011). Moreover, much of Thai life centers around the local wat (temple or monastery) where people come for worship, sermons, advice on family matters, meditation, schooling for children, and traditional medicine (Dhammathai, n.d.). Thus, mediation practice, Vipassana or retreat minds are seem to be a part in wellness tourism in Thailand at these days.

Expecially, Roi-Kaen-San-Sin cluster is a pseudonym of the cultural prosperity destination areas of Roi-et, KhonKaen, Mahasarakam, and Kalasin Provinces in Thailand (Kovathanakul, 2013). This cluster is established officially 
on 2003 to develop economic potential in the northeasten of Thailand which was formerly declared a land of poverty (Naipinit et al., 2013). This area is comprised of many well-known temples and meditation practice places such as Weluwana temple in KhonKaen province, Phra MahaChedi Chai Mongkol in Roi Et province, Wat Pa Wang Nam Yen in Mahasarakham provinces.

Therefore, the researchers focus on investigate problems on meditation practice destination, and temples which serves retreat meditation as well in Roi-Kaen-San-Sin cluster to define1) what tourists' opinions on wellness tourism in Roi-Kaen-San-Sin cluster, Thailand is and 2) what guidelines to develop wellness tourism in Roi-Kaen-San-Sin cluster, Thailand should be.

\section{Literature Review}

\subsection{Background of Roi-Kaen-San-Sin Cluster}

Roi-Kaen-San-Sin cluster is comprised of Roi Et, KhonKaen, Mahasarakham and Kalasin which are provinces on northeastern region in Thailand. Roi-Kaen-San-Sin cluster was set up by the Thai government in 2003 to develop a network for increasing the economic potential in the northeastern, Thailand (Naipinit et al., 2013).

In term of tourism, Roi-Kaen-San-Sin cluster is defined by cultural tourism as identity of this cluster. There are many reglious and cultural destinations which is famous and popular, such as Nong Wang Royal Temple in KhonKaen province, or Klang Ming Muang Royal Temple in Roi Et province.

Additional, this cluster also situated on Mittraparp Road, the highway and gateway to Route No.9, which links to Laos and Vietnam. It seems to be an opportunity to develop regional tourism in Roi-Kaen-San-Sin cluster (Kovathanakul, 2013).

\subsection{Components of tourism destination}

Destination is the terminus of tourists' holiday which is a complex link between geography and tourism (Malizu,2010). It is consitent with Leiper(1995) state that destinations are places where people travel and stay for a while to experience certain features or attractions. World Tourism Organization (2007) states that destination includes tourism products such as support services and attractions and other tourist resources, basic elements which attract tourists and satisfy their demand on arrival. There are attractions, public and private amenities, accessibility, human resources, image and character and price. Apart from that, Buhalis (2000) also suggests most destinations comprise of a core of the following components named as the 6 As framework, which includes attraction, accessibility, amenities, available packages, activities and ancillary services. This framework is the amalgam of tourism products, offering an integrated experience to tourists.

In other hand, destination is seem to be a push factor to enhance tourism development, because it brings all element components together in a unique image to communicate and fascinate tourists. As Felicia et al. (2009) state all tourist destinations have an image and the interest of the marketers is to clearly distinguish it from the other destinations. Thus, attitudes of perceptions have an important role in the selection of tourists destination. That is why destination management organization or planner should focus on public relation and advertising activities to promote image of destination and to create travelling experiences which tourist will find (Molina et al., 2010).

\subsection{Wellness Tourism}

In recent year, health and wellness tourism has grown exponentially (Bushell\& Sheldon, 2009) which is being increasingly recognized as a crucial aspect of tourism, both nationally and internationally (Hartwell, 2014). This includes visits to spas, thermal baths, wellness hotel and spiritual or holistic retreats (Smith \&Puczko, 2009). In term of wellness tourism, It focuses on preventative, lifestyle-based approaches to health, with an emphasis on the mental, psychological, emotional and spiritual aspects of health (Smith, 2013).

There is a global movement recognising that the health of the population is not merely the responsibility of the health services but is a wide multi-sectoral social issue (Hartwell, 2014). Many people visit holistic retreat centres with the aim of healing their life or seeking greater meaning. Holistic implies that the deal with the whole person and the integration of body, minds and spirits as well as domains (Kelly \& Smith, 2009). Smith (2013) states wellness tourism makes people consider their own mortality and preserve their lives and health as long as possible. They may attempt to foster a greater sense of spirituality. 
Kelly (2010) argues wellness tourism istaking onan important role in fulfilling certain new functions of stress management, personal development, reflection, connection and meaning in their way of lifes. Traditional tourism escapes involving hedonistic behaviour, blocking out the banal or simply'switching off' (Cohen, 1996), is now being joined by new forms of tourism that focus on health and a sense of discovery or purpose for the self.

\section{Research Objectives}

For this research, the following issues of study were specified

- To study tourists' opinions on wellness tourism in Roi-Kaen-San-Sin cluster, Thailand.

- To study guidelines to develop wellness tourism in Roi-Kaen-San-Sin cluster, Thailand.

\section{Research Methodology}

To ensure the study was objective, the researchers employed quantitative research methods, qualitative research methods or a mixed method approach as shown below:

\subsection{To study tourists' opinions on wellness tourism in Roi-Kaen-San-Sin cluster, Thailand.}

For the quantitative data, the participants were tourists who travel to Roi-Kaen-San-Sin cluster, Thailand. The questionnaire consisted of two parts: 1) demographic information including sex, age, educational level, marital status and income; 2) tourists' opinions on wellness tourism in Roi-Kaen-San-Sin cluster, Thailand which was considered in seven aspects that included: attitudes, attractions, accessibility, accommodations, amenities, activities and advertising. The questionnaire used multiple choice questions in which respondents select one of the alternative possible answers and Likert scales with five options: strongly agree, agree, not sure, disagree and strongly disagree. The researchers interpreted the completed questionnaires by dividing the question scale into a 5 point scale, as shown in table 1:

Table 1. Significance of points

\begin{tabular}{cc}
\hline Average Scores & Levels of Significant \\
\hline $1.00-1.80$ & Lowest \\
$1.81-2.60$ & Low \\
$2.61-3.41$ & Moderate \\
$3.42-4.20$ & High \\
$4.21-5.00$ & Highest \\
\hline
\end{tabular}

For the tourists who come to Roi-Kaen-San-Sin cluster, researchers applied Yamane's formula (1973) to calculate the sampling size as 400 . The statistical analysis of the data used the mean, standard deviation and Chi-square tests.

\subsection{To study guidelines to develop wellness tourism in Roi-Kaen-San-sin cluster, Thailand.}

For the qualitative data collection, a focus group discussion was organized. There were twelve experts including academics, planners, tourism entrepreneurs and representatives of involved public organizations and local philosophers. The group discussed the appropriate guidelines to develop wellness tourism in Roi-Kaen-San-Sin cluster, Thailand. Data analysis was performed using descriptive analysis. 


\section{Research Area}

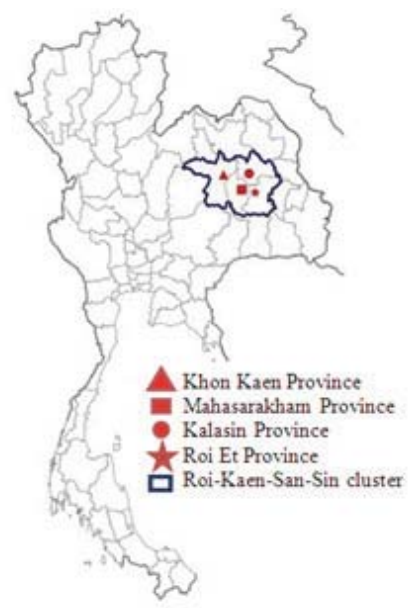

Figure 1. Research area

In this study, researchers focus on Roi-Kaen-San-Sin clusters, Thailand as research area (Shown as figure 1). This cluster is established officially on 2003. Nowadays, this area is important area in northeastern of Thailand about economic and tourism potential. This area is comprised of many famous temples and meditation practice places such as Weluwana temple in KhonKaen province, Phra MahaChedi Chai Mongkol in RoiEt province, Wat Pa Wang Nam Yen in Mahasarakham provinces. Almost tourist arrivesRoi-Kaen-San-Sin clusters to pay homage sacred Buddhist status, make merit and relax their minds.

\section{Research Result}

\subsection{Tourists' opinions on wellness tourism in Roi-Kaen-San-Sin cluster, Thailand}

Table 2. Tourists'opinions on wellness tourism in Roi-Kaen-San-Sin clusters, Thailand

\begin{tabular}{|l|c|c|c|}
\hline Items & X & S.D & Interpretation \\
\hline Attractions & & & \\
\hline Popular wellness destination for tourists & 4.43 & 0.55 & Highest \\
\hline Identity of local cultures in wellness destination & 4.29 & 0.65 & Highest \\
\hline Fascinating landscapes & 4.33 & 0.54 & Highest \\
\hline Image of wellness destination & 4.40 & 0.52 & Highest \\
\hline Attitudes & & & \\
\hline Welcoming for host community in wellness destination & 4.50 & 0.50 & Highest \\
\hline Reflect yourself during stay in wellness destination & 4.48 & 0.60 & Highest \\
\hline Good experience to apply in your daily & 4.42 & 0.52 & Highest \\
\hline Re-visiting again & 4.53 & 0.53 & Highest \\
\hline Accessibility & & & High \\
\hline Conditional road & 3.52 & 0.50 & Moderate \\
\hline Convenience transport system & 3.32 & 0.56 & High \\
\hline Explicitly sign along the ways & 3.48 & 0.50 & Moderate \\
\hline Public transportation & 3.28 & 0.67 & \\
\hline Accommodation & & & Highest \\
\hline Clean and convenience & 4.30 & 0.70 & High \\
\hline The adequacy of the number of lodges & 4.13 & 0.58 & Highest \\
\hline Reflecting cultural identity of wellness destination & 4.42 & 0.49 & Highest \\
\hline Safe and security & 4.25 & 0.63 & High \\
\hline Suitable prices & 4.04 & 0.63 & \\
\hline Activities & & & \\
\hline Diversity activities suitable for tourist & 3.86 & 0.61 & High \\
\hline Meditation practice activity & 3.41 & 0.63 & High \\
\hline
\end{tabular}




\begin{tabular}{|l|c|c|c|}
\hline Learning Buddhist Dharma & 3.45 & 0.62 & High \\
\hline Experience local cultural experience & 3.65 & 0.56 & High \\
\hline Amenities & & & \\
\hline Infrastructures for tourists (water/ electricity supply) & 3.43 & 0.62 & High \\
\hline Restroom management & 2.50 & 0.50 & Low \\
\hline Local dishes & 2.10 & 0.59 & Low \\
\hline Emergency treatment & 3.19 & 0.78 & Moderate \\
\hline Advertising & & & \\
\hline Tourists information center & 3.35 & 0.67 & Moderate \\
\hline Online advertising & 2.71 & 0.62 & Moderate \\
\hline Brochures/ pocketbook & 3.30 & 0.65 & Moderate \\
\hline Convenience to track information & 2.80 & 0.67 & Moderate \\
\hline Reliability information & 3.82 & 0.67 & High \\
\hline Total & 3.72 & 0.11 & High \\
\hline
\end{tabular}

Table 2 shows the results' of this study on tourists'opinions on wellness tourism in Roi-Kaen-San-Sin clusters, Thailand. Each aspect of these finding is interpreted as below:

For attractions, popular wellness destination for tourists is at the highest level (average $=4.43$, S.D. $=0.55$ ). Identity of local cultures in wellness destination is at the highest level (average $=4.29$, S.D. $=0.65$ ). Fascinating landscapes is at the high level (average $=4.33$, S.D. $=0.54$ ). Image of wellness destination is at the high level (average $=$ 4.40, S.D. $=0.52$ ).

In term of attitudes, welcoming for host community in wellness destination is at the highest level (average $=4.50$, S.D. $=0.50$ ). Reflect yourself during stay in wellness destination is at the highest level (average $=4.48, S . D .=0.60$ ). Good experience to apply in your daily is at the highest level (average $=4.42$, S.D. $=0.52$ ). Re-visiting again is at the highest level (average $=4.52$, S.D. $=0.53$ ).

On accessibility, conditional road is at a high level (average $=3.52$, S.D. $=0.50$ ). Explicitly sign along the ways is at a high level (average $=3.48$, S.D. $=0.50)$. Convenience transport system is at a moderate level (average $=3.32$, S.D. $=$ 0.56). Public transportation is at a moderate level (average $=3.28$, S.D. $=0.67$ ).

For accommodation, clean and convenience is at the highest level (average $=4.30$, S.D. $=0.70$ ). Reflecting cultural identity of wellness destination is at the highest level (average $=4.42$, S.D. $=0.48$ ). Safe and security is at the highest level (average $=4.25$, S.D. $=0.63$ ). The adequacy of the number of lodges is at a high level (average $=4.13$, S.D. $=0.58$ ). Suitable prices is at a high level (average $=4.04$, S.D. $=0.63$ ).

On activities, diversity activities suitable for tourists is at a high level (average $=3.86$, S.D. $=0.61$ ). Meditation practice activities is at a high level (average $=3.41$, S.D. $=0.63$ ). Learning Buddhist Dharma is at a high level (average $=$ 3.45 , S.D. $=0.62$ ). Experience local cultural experience is at a high level (average $=3.65$, S.D. $=0.56$ ).

For amenities, infrastructures for tourists (water/ electricity supply) is at a high level (average $=3.43$, S.D. $=0.62$ ). Emergency treatment is at a moderate level (average $=2.10$, S.D. $=0.59$ ). Restroom management is at a low level (average $=2.50$, S.D. $=0.50)$. Local dish is at a low level (average $=2.50$, S.D. $=0.50)$.

On advertising, reliability information is at a high level (average $=3.82$, S.D. $=0.67$ ). Tourists information center is at a moderate level (average $=3.34$, S.D. $=0.67$ ). Online advertising is at a moderate level (average $=2.71$, S.D. $=0.62$ ). Brochures/ pocketbooks is at a moderate level (average $=3.30$, S.D. $=0.65$ ). Convenience to track information is at a moderate level (average $=2.80$, S.D. $=0.67$ ).

On conclusion, tourists' opinions on wellness tourism in Roi-Kaen-San-Sin clusters is at a high level. The researchers identified each aspect from the highest level to lowest level shown in table 3.

Table 3. Summary of tourists' opinions in 7 aspects of wellness tourism

\begin{tabular}{|c|c|c|c|}
\hline Items & X & S.D & Interpretation \\
\hline Attractions & 4.36 & 0.28 & Highest \\
\hline Attitude & 4.48 & 0.26 & Highest \\
\hline Accommodation & 4.23 & 0.26 & Highest \\
\hline Activities & 3.59 & 0.29 & High \\
\hline Accessibility & 3.40 & 0.29 & Moderate \\
\hline Amenities & 2.80 & 0.31 & Moderate \\
\hline Advertising & 3.20 & 0.27 & Hoderate \\
\hline Total & 3.72 & 0.11 & High \\
\hline
\end{tabular}


Table 3 shows that tourists' opinions on wellness tourism in Roi-Kaen-San-Sin clusters in term of attraction, attitude and accommodation are at the highest level while activities and advertising are at the high level and accessibility, amenities and advertising are all at a moderate.

\subsection{Guidelines to develop wellness tourism in Roi-Kaen-San-Sin cluster, Thailand}

Based on the result of questionnaires, a focus group discussion was organized. Twelve experts including academics, planners, tourism entrepreneurs and representatives of involved public organizations and local philosophers discussed and proposed guidelines to develop wellness tourism in Roi-Kaen-San-Sin cluster, as detailed below:

\subsubsection{Improving facilities for tourists}

Public utilizes are necessary to serve tourists during spend on in wellness destination. Thus, retreat operators and host of wellness destinations should improve quality of infrastructure to facilitate tourists more convenience. This issue also reflects readiness of destination in tourism development.

\subsubsection{Promoting wellness tourism through advertising activities}

Advertising activities will bring destination image to tourists. It is crucial process in successful tourism management. RoiKaen-San-Sin clusters should create an official website of wellness tourism which includes reliability information about wellness destinations such as local temple, meditation practice places, wellness activities. Apart from that, brochures and leaves about wellness tourism in this cluster should be published and distribute in tour agents, bus stations, hotels. It is convenience to approach Thai tourists and international tourists.

\subsubsection{Publish map direction of wellness destination in Roi-Kaen-San-Sin Cluster}

Roi-Kaen-San-Sin cluster is comprised of many temples and meditation practice places which are popular to tourists. It is crucial to connect these destinations in a map for wellness destination particularly which tourists can find and plan their wellness trip effectively. Tourism management organizations, entrepreneurs, local philosophers and host of wellness destinations should cooperate to collect information of destinations and plan map direction of wellness tourism in RoiKaen-San-Sin cluster.

\subsubsection{Diversity wellness activities for tourists}

Culture is an essential part of the wellbeingexperience. Apart from meditation practice or mind retreat, host of wellness destinations should create cultural activities to enhance tourists' awareness on local way of life. There are training local food, learning about local handicraft and so on. These activities will establish connection between host community and tourists, make them to understand each other and bring the happiness to them.

\section{Conclusion}

This study aims to investigate problem on wellness tourism in Roi-Kaen-San-Sin cluster, Thailand. Researchers applied mix method to ensure the research objectives. Research data is collected from questionnaires and focus group discussion. The results showed that on overall, tourists' opinions on wellness tourism in Roi-Kaen-San-Sin clusters is at a high level in which attraction, attitude and accommodation are at the highest level while activities and advertising are at the high level and accessibility, amenities and advertising are all at a moderate. The guidelines to develop wellness tourism in Roi-Kaen-San-Sin cluster was proposed which is comprised 1) improving facilitates for tourists 2) promoting wellness tourism through advertising activities 3) publish map direction of wellness destination in Roi-Kaen-San-Sin cluster and 4) diversity wellness activities for tourists.

\section{References}

Buhalis, D. (2000). Marketing the competitive destination of the future. Tourism management 21, $97-116$. Retrieved from http://dx.doi.org/10.1016/S0261-5177(99)00095-3. 
Bushell, R \& Sheldon, P. (2009).Wellness and Tourism: Mind, Body, Spirit, Place. New York: Cognizant.

Cohen, E. (1996). A phenomenology of tourist experiences. In Y.Apostopoulos, S. Leivadi\& A. Yiannakis (Eds.), The sociology of tourism: Theoretical and empirical investigations. London:Routledge. pp. 90-111.

Dhammathai (n.d.).The meditation places in Thailand: A guildeline to Meditation Centres in Thaialnd.Retrieve from http://www.dhammathai.org/e/meditation/page1.php

Euromonitor International. (2011). Health and Wellness Tourism in Thailand. Retrieved from http://www.euromonitor.com/health-andwellness-tourism-in-thailand/report.

Felicia, S., Părgaru, I., Elena, M.M. (2009). The destination brand, some conceptual methodologic guidelines in the destination marketing.Proceedings of The 2nd International Tourism Conference: "Sustainable mountain tourism - local responses for global changes",DrobetaTurnuSeverin, 26-27 Sept. 2009, Universitaria Publishing House, Craiova.

Hartwell, H. (2014). Book review: Wellness Tourism: A Destination Perspective. Tourism Management 42, 305-306

Kelly, C. (2010). Analysing wellness tourism provision: A retreat operators' study.Journal of Hospitality and Tourism Management, 17, 108-116.

Kelly, C. \& Smith, M.K. (2009). Holistic Tourism: Integrating body, mind and spirit. In: Bushell, R. and Sheldon, P. (eds). Wellness and Tourism: Mind, Body, Spirit, Place. New York: Cognizant, pp.69-83.

Kovathanakul, D (2013). Roi - Kaen - San - Sin destination branding. The challenge of responsible tourism in Thailand for AEC.International Journal for Responsible Tourism 2(2), 41-54.

Le Serre, D. (2008). Who is the senior consumer for the tourism industry? Amfiteatru Economic, 10 (special 2), 195-206

Leiper, N. (1995). Tourism Management. Melbourne: RMIT press.

Malizu, M.(2010). Key elements of a Model for Sustanable Tourism.International Journal of Energy and Environment, 2(4), 45-54.

Molina, A., Gómez, M. \&Martín-Consuegra, D. (2010).Tourism marketing information and destination imagemanagement. African Journal of Business Management.4(5), 722-728.

Naipinit, A., Maneenetr, T., Na Sakolnakorn, T.P.,Churngchow, C. \&Kroeksakul, P. (2013). SWOT Analysis of Religious Tourism in the RoiKaenSarn Sin Cluster of Northeastern Thailand. Asian Social Science, 9(13), 262-269.

Pesonen, J., \&Komppula, R. (2010). Rural wellbeing tourism: Motivations and expectations [Special section].Journal of Hospitality and Tourism Management,17, 150-157.

Smith, M. (2013).Transforming Quality of life through Wellnes Tourism.In Y. Reisinger (Ed).Transformational Tourism: Tourist Perspectives. Oxfordshire, UK: CABI. Pp55-67.

Voigt, C., Brown, G. \& Howat, G. (2011). Wellness tourists: in search of transformation. Tourism Review 66 (1/2), 16-30.

World Tourism Organization. (2007). A Practical Guide to Tourism Destination Management. Madrid: World Tourism Organization.

Yamane, T. (1973). Statistic: An Introductory Analysis. New York: Harper and Row. 